\title{
Cure Behavior of an Epoxy-Anhydride-Imidazole System
}

\author{
Won Ho Park, Jong Keun LeE, ${ }^{\dagger}$ and Kee Jeong KwON* \\ Department of Polymer Science and Engineering, Kumoh National University of Technology, \\ Kumi, Kyungbuk 730-701, Korea \\ *288-11, Cheil Ciba-Geigy Co., Ltd., Kong Dan Dong, Kumi, Kyungbuk 730-030, Korea
}

(Received September 13, 1995)

\begin{abstract}
The cure behavior of an epoxy-anhydride system with one of imidazole derivatives as an accelerator was investigated for both stoichiometric and epoxy-rich formulations. The mixtures were isothermally cured for different times at various temperatures, and the glass transition temperature $\left(T_{\mathrm{g}}\right)$ was determined by differential scanning calorimetry (DSC). There was a considerable increase in the $T_{\mathrm{g}}$ during curing, and master curves were formed by shifting and superposing the $T_{\mathrm{g}}$ $v s$. cure time curves. The activation energies obtained by the shift were $15.2 \mathrm{kcal} \mathrm{mol}^{-1}$ and $16.5 \mathrm{kcal} \mathrm{mol}^{-1}$ for the stoichiometric and epoxy-rich systems, respectively. For the epoxy-rich one, plateaus were observed on the $T_{\mathrm{g}} v s$. cure time curves, and two exothermic peaks appeared on DSC curves in the early stage of cure and became one thereafter. This phenomenon is related to the competitive reactions between esterification and etherification reactions. We found that the maximum $T_{\mathrm{g}} \mathrm{s}$ were $80^{\circ} \mathrm{C}$ for esterification and $125^{\circ} \mathrm{C}$ for etherification in the excess epoxy system.

KEY WORDS Epoxy / Anhydride / Imidazole / Glass Transition Temperature / Esterification / Etherification /
\end{abstract}

During curing of thermosetting materials, low molecular liquids are transformed to high molecular solids by chemical reactions. As the cure proceeds, there is a considerable increase in the glass transition temperature $\left(T_{\mathrm{g}}\right)$. It is known that the $T_{\mathrm{g}}$ can be used as a measure of chemical conversion, especially, in the later stages of cure, where the $T_{\mathrm{g}}$ changes more sensitively with conversion. ${ }^{1}$ Variation of $T_{\mathrm{g}}$ with cure time has been studied for dicyanate ester-polycyanurate ${ }^{2,3}$ and epoxyamine systems. ${ }^{1,4,5}$ Since $T_{\mathrm{g}}$ is an important parameter in analyzing cure behavior, we examined the variation of $T_{\mathrm{g}}$ in the relation to the cure reaction mechanisms for a catalyzed epoxy-anhydride system.

It is known that catalyzed reaction of epoxy resins with anhydrides proceeds through two principal curing reactions; esterification and etherification. Although the conflicting initiation mechanisms are reported, ${ }^{6-8}$ the initiation of epoxy group by tertiary amine produces a zwitterion as in eq $1 .{ }^{9}$

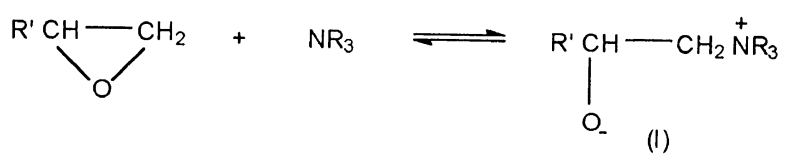

An alkoxide anion from the epoxy backbone reacts with the anhydride to give a monoester (eq 2), which reacts with an epoxy group to give the diester (eq 3). A competing reaction is the epoxy with an alkoxide anion resulting in an ether linkage (eq 4).

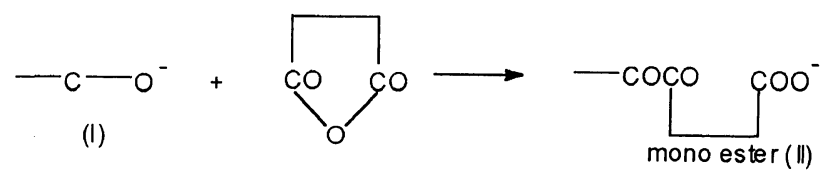

\footnotetext{
$\dagger$ To whom all correspondence should be addressed.
}

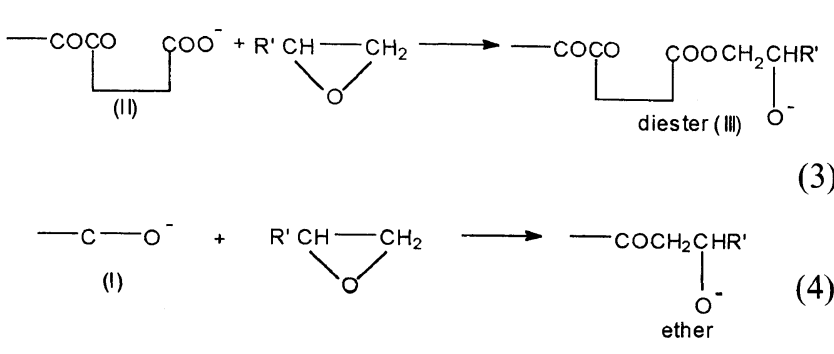

The etherification reaction of an epoxy with alkoxide anion has been known to be slower than the esterification reaction of alkoxide anion with anhydride or carboxylate anion with epoxy. ${ }^{10,11}$ Etherification of epoxy resins in epoxy-amine curing systems has already been reported by many researchers. ${ }^{4,5,12}$

\section{EXPERIMENTAL}

\section{Materials}

Epoxy resin for this study was a diglycidyl ether of bisphenol A (DGEBA) (Kumho Shell Chemical Co., Epikote 828 , equivalent weight $=186 \mathrm{~g} \mathrm{~mol}^{-1}$ ). It was cured with a mixture of methyltetrahydrophthalic anhydride (MTHPA) and hexahydrophthalic anhydride (HHPA) (Lonza Italia, equivalent weight $=161 \mathrm{~g} \mathrm{~mol}^{-1}$, mixing ratio by weight $=6 / 4$ ) as a hardener in the presence of a 1-cyanoethyl-2-ethyl-4-methyl imidazole (2E4MZ$\mathrm{CN}$, shikoku Chemicals Co.) as an accelerator. The chemical structures of the reactants are shown in Figure 1.

The chemicals were mechanically well mixed for $10 \mathrm{~min}$ at $40^{\circ} \mathrm{C}$ to obtain a homogeneous mixture. After mixing, the mixture was immediately stored in a refrigerator maintained at $-70^{\circ} \mathrm{C}$ to prevent any further reaction. The compositions of the epoxy/anhydride/imidazole by weight were 100/90/1.5 (I) for a stoichiometric ratio, and $100 / 50 / 1.5$ (II) for an epoxy-excess formulation.

\section{Cure Monitoring Technique}

Differential scanning calorimetry (DSC, Du Pont 910)

(1)
(n) 


\section{Epoxy resin}

DGEBA $(n=0.11)$<smiles>CC(C)(C)OCC(O)COc1ccc(C(C)(C)c2ccc(C(C)(C)O)cc2)cc1</smiles><smiles>Cc1ccc(C(C)(C)c2ccc(OCC3CO3)cc2)cc1</smiles>

Hardener

MTHPA<smiles>CC1=CCC2C(=O)OC(=O)C2C1</smiles>

HHPA<smiles>O=C1OC(=O)C2CCCCC12</smiles>

\section{Accelerator}

2E4MZ-CN<smiles>CCC1=NC(C)C2CCCCC12</smiles>

Figure 1. Chemical formulae of the reactants.

was employed to measure $T_{\mathrm{g}}$ in this experiment. The initial mixture in a vial was taken out of a refrigerator, and allowed around $15 \mathrm{~min}$ at room temperature until the condensed moisture on the surface of the vial with the cold material was completely evaporated. Approximately $10-15 \mathrm{mg}$ of the mixture was put into a DSC hermetic pan and then sealed by crimping. The sealed pan with sample was isothermally cured in dry oven for prespecified periods ( $10 \mathrm{~min}$ to $72 \mathrm{~h}$ ) at different cure temperatures.

The cure temperatures in this study were $60,75,90$, $105,120^{\circ} \mathrm{C}$ for sample (I), and $75,85,95,105^{\circ} \mathrm{C}$ for sample (II). The samples uncured or cured at shorter periods were quenched down to $-60^{\circ} \mathrm{C}$ and then subjected to temperature scans from $-60^{\circ} \mathrm{C}$ to $220^{\circ} \mathrm{C}$ at $10^{\circ} \mathrm{C} \mathrm{min}^{-1}$. Temperature scans for other samples were from room temperature to $220^{\circ} \mathrm{C}$ at the same rate of heating. From these scans, we are able to determine $T_{\mathrm{g}}$ and examine residual exothermic peaks by cure reactions.

The $T_{\mathrm{g}}$ appeared as an endothermic shift over a temperature interval in the DSC scan. When an endothermic peak was developed during the first scanning up through $T_{\mathrm{g}}$, the peak was eliminated and obtained a stepwise transition by heating the samples to just above the endothermic peak, followed by quenching to room temperature at $30^{\circ} \mathrm{Cmin}^{-1}$ in the DSC cell. Similar methods were used for same purpose. ${ }^{1,13}$ Then the samples were reheated to $220^{\circ} \mathrm{C}$. In this study, $T_{\mathrm{g}}$ was taken as the inflection point of the step-transition.

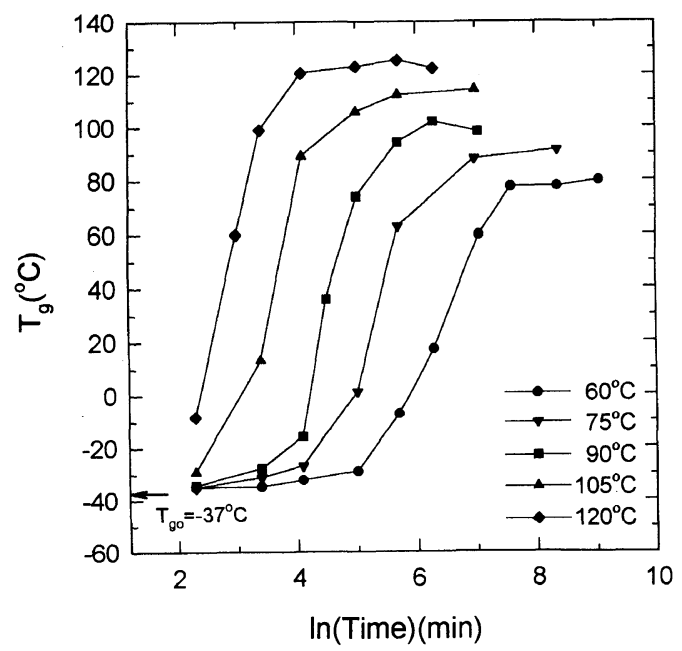

Figure 2. $T_{\mathrm{g}} v s$. cure time of samples at various temperatures for a stoichiometric ratio.

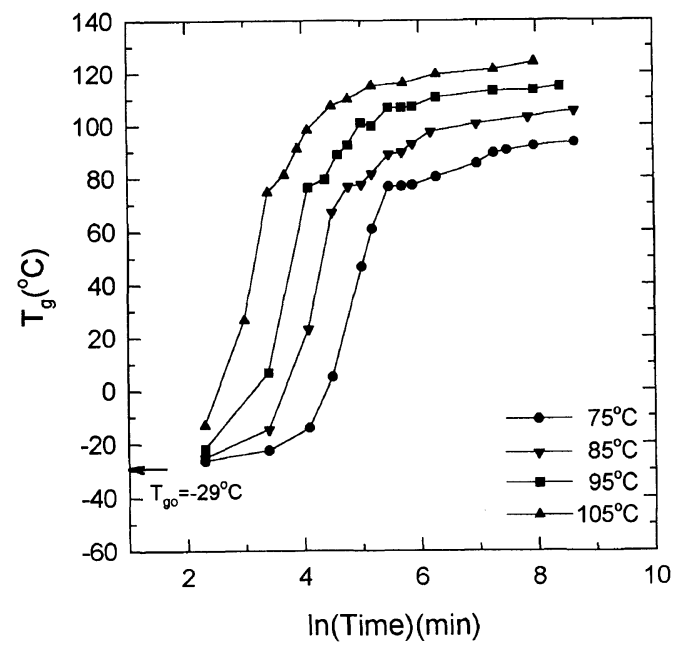

Figure 3. $T_{\mathrm{g}} v s$. cure time of samples at various temperatures for an epoxy-rich formulation.

\section{RESULTS AND DISCUSSION}

The glass transition temperature $\left(T_{\mathrm{g}}\right)$ of samples cured at various times and temperatures for stoichiometric (I) and epoxy-rich (II) systems was measured and shown in Figures 2 and 3 , respectively. The $T_{\mathrm{g}} \mathrm{s}$ of uncured samples $\left(T_{\mathrm{g} 0}\right)$ were $-37^{\circ} \mathrm{C}$ for sample $(\mathrm{I})$ and $-29^{\circ} \mathrm{C}$ for sample (II) as marked by arrows in the figures. Since the viscosity of epoxy resin is higher than that of anhydride in our experiment, the higher $T_{\mathrm{g}}$ of sample (II) is due to the larger ratio of epoxy resin in the sample. The $T_{\mathrm{g}}$ increases up to above $120^{\circ} \mathrm{C}$ for sample (I) cured at $120^{\circ} \mathrm{C}$ for $70 \mathrm{~min}$ and sample (II) cured at $105^{\circ} \mathrm{C}$ for $400 \mathrm{~min}$. The increase of the $T_{\mathrm{g}}$ levels off at long times, indicating the completion of cure reaction. The trend of the $T_{\mathrm{g}}$ increase in these figures has an S-shape as in other thermosetting systems. ${ }^{1,4}$ With increasing the cure temperature, the $\mathrm{S}$-shaped curves shift to shorter time scales. In Figure 3 for the excess epoxy sample (II), we can observe plateaus at around $T_{\mathrm{g}}=80^{\circ} \mathrm{C}$ for all samples, which become more distinct at lower temperatures. This phenomenon has also been observed in an epoxy-amine system, ${ }^{5}$ which will be discussed later in this study. 


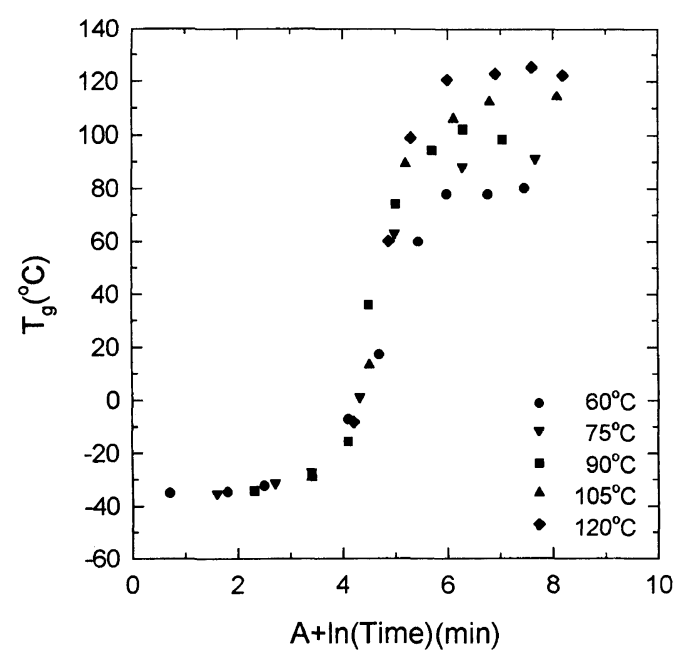

Figure 4. Superposition of the $T_{\mathrm{g}} v s$. $\ln$ (time) curves to form a master curve for a stoichiometric ratio $\left(T_{\mathrm{r}}=90^{\circ} \mathrm{C}\right)$.

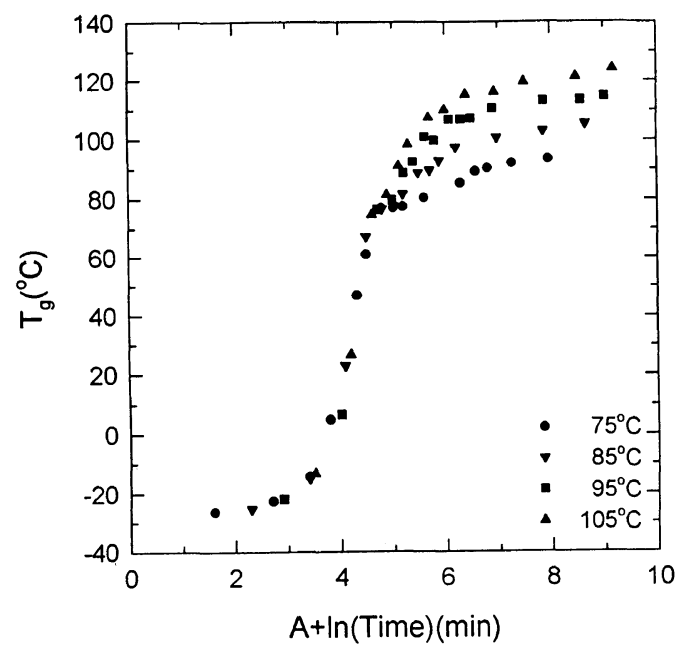

Figure 5. Superposition of the $T_{\mathrm{g}} v s \cdot \ln ($ time) curves to form a master curve for an epoxy-rich formulation $\left(T_{\mathrm{r}}=85^{\circ} \mathrm{C}\right)$.

The $T_{\mathrm{g}}$ vs. $\ln$ (time) curves shown in Figures 2 and 3 were time-temperature shifted horizontally and master curves were formed at the initial stage of cure. The master curves are shown in Figures 4 and 5 at selected reference temperatures, $90^{\circ} \mathrm{C}$ and $85^{\circ} \mathrm{C}$, respectively.

The reaction rate in a kinetically controlled region is expressed by the following Arrhenius rate equation:

$$
\frac{\mathrm{d} \alpha}{\mathrm{d} t}=A \exp \left(\frac{-E_{\mathrm{a}}}{R T_{\mathrm{c}}}\right) f(\alpha)
$$

where $E_{\mathrm{a}}$ is the apparent activation energy for the overall reaction, $T_{\mathrm{c}}$ is the cure temperature, and $f(\alpha)$ is a function of conversion $(\alpha)$ which is independent of temperature. By rearranging and integrating eq 5 , we obtain

$$
\ln \int_{0}^{\alpha} \frac{\mathrm{d} \alpha}{f(\alpha)}=\ln A+\ln t-\frac{E_{\mathrm{a}}}{R T_{\mathrm{c}}}
$$

Since there is a unique relationship between $\alpha$ and $T_{\mathrm{g}}$, eq 6 may be written as:

$$
F\left(T_{\mathrm{g}}\right)=\ln A+\ln t-\frac{E_{\mathrm{a}}}{R T_{\mathrm{c}}}
$$

At the arbitrary reference temperature $\left(T_{\mathrm{r}}\right)$, eq 7 becomes

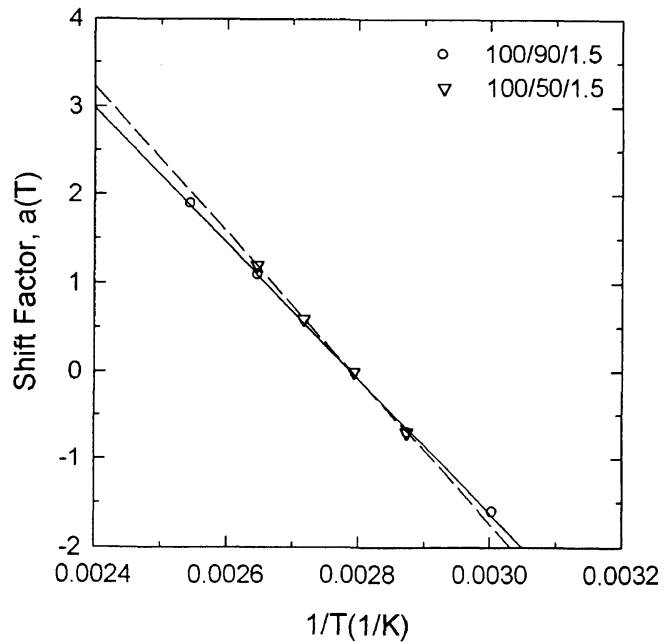

Figure 6. Arrhenius plot of the shift factors.

\begin{tabular}{|c|c|c|}
\hline Materials & $\begin{array}{c}\text { Activation } \\
\text { energy }\left(\mathrm{kcal} \mathrm{mol}^{-1}\right)\end{array}$ & Reference \\
\hline DGEBA-TMAB ${ }^{\mathbf{a}}$ & 15.2 & 5 \\
\hline Epoxy Novolac-DDS ${ }^{b}$ & 14.6 & 4 \\
\hline \multicolumn{3}{|c|}{ DGEBA-anhydride-imidazole } \\
\hline $100 / 90 / 1.5$ & 15.2 & This work \\
\hline $100 / 50 / 1.5$ & 16.5 & This work \\
\hline
\end{tabular}

Table I. Activation energies for epoxy systems obtained by $T_{\mathrm{g}}$-shift

${ }^{\mathrm{a}} \mathrm{TMAB}$, trimethylene glycol di-p-aminobenzoate. ${ }^{\mathrm{b}} \mathrm{DDS}, 4.4^{\prime}$ diaminodiphenylsulfone.

$$
F\left(T_{\mathrm{g}}\right)=\ln A+\ln t_{\mathrm{r}}-\frac{E_{\mathrm{a}}}{R T_{\mathrm{r}}}
$$

By subtracting eq 7 from eq 8 , a shift factor $(a(T))$ may be calculated as follows:

$$
a(T)=\ln t_{\mathrm{r}}-\ln t=\left(-\frac{E_{\mathrm{a}}}{R}\right)\left(\frac{1}{T_{\mathrm{c}}}-\frac{1}{T_{\mathrm{r}}}\right)
$$

Plotting the shift factors used to form the master curves for both mixtures as a function of reciprocal temperature gives a straight line with a slope, $-E_{\mathrm{a}} / R$, as shown in Figure 6. The apparent activation energy can be determined from eq 9 . In this study, the activation energies calculated were $15.2 \mathrm{kcal} \mathrm{mol}^{-1}$ and $16.5 \mathrm{kcal} \mathrm{mol}^{-1}$ for samples (I) and (II), respectively. Table I contains the apparent activation energies obtained by the timetemperature shift of $T_{\mathrm{g}}$ with the values for other systems. It is considered that the higher value in sample (II) may indicate the slower rate of reaction involved.

In Figure 7, residual exothermic peaks above $T_{\mathrm{g}}$ on DSC curves were shown for the excess epoxy samples isothermally cured at different times $(90,150,300,540$, $5760 \mathrm{~min}$ ) at $75^{\circ} \mathrm{C}$. In the initial stage of cure (90 and $150 \mathrm{~min}$ ), there exist two exothermic peaks on the DSC curve. However, the area of the first peak decreases significantly with cure time, while that of the second hardly changes until the first one completely disappeared. In the later stage $(300,540$, and $5760 \mathrm{~min})$, the area of the remaining second exotherm decreases with further curing. This variation of the peaks may be due to two different cure reactions, esterification and etherification. 


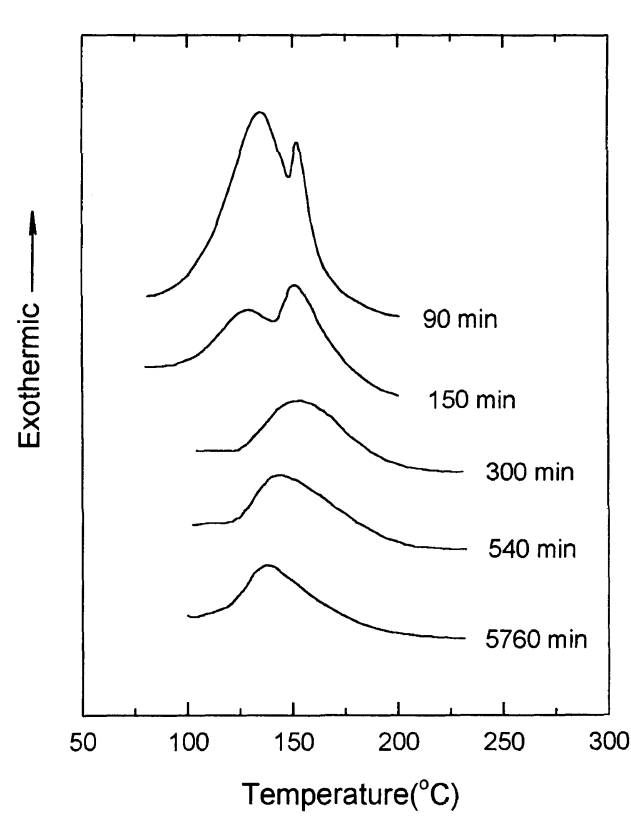

Figure 7. DSC scans of samples cured at $75^{\circ} \mathrm{C}$ for various cure times for an epoxy-rich formulation.

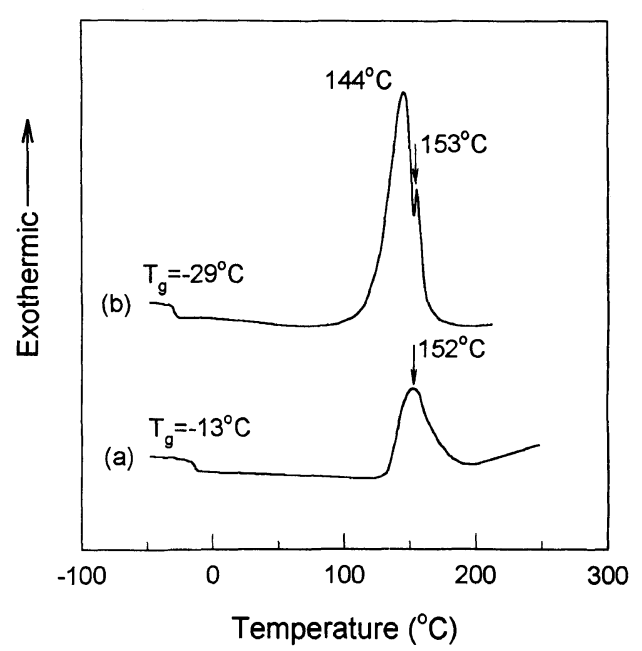

Figure 8. Comparison of DSC scans for epoxy-imidazole (a) and excess epoxy-anhydride-imidazole (b) systems.

During the whole curing process, the peak positions tend to shift lower temperatures. The temperature of the second peak after curing for 5760 min decreased almost down to that of the first peak in the early stage of cure.

Since it is known that the dominant reaction in an epoxy-imidazole system is etherification, ${ }^{14,15}$ a dynamic temperature scan was made for the epoxy resin having only imidazole (2E4MZ-CN) without anhydride by DSC. From this experiment we may figure out the reaction mechanism in the excess epoxy-anhydride-imidazole system. The mixing ratio for this test was epoxy/ imidazole $=100 / 1.5$ and the procedure for making the sample was same as the other mixtures. The DSC scans of uncured samples for the epoxy-imidazole and epoxyrich systems are shown in Figure 8. The $T_{\mathrm{g}}$ in the epoxy-imidazole system was $-13^{\circ} \mathrm{C}$ which is higher than that in the epoxy-rich system. This is simply because the epoxy-imidazole sample has no anhydride. And in the epoxy-imidazole system only one exothermic peak appeared at $152^{\circ} \mathrm{C}$. This temperature nearly corresponds to the peak temperature of the second exotherm in the epoxy-rich system as marked by arrows. It means that the cure reaction mechanism of the epoxy-imidazole system is identical with that of the epoxy-rich formulation at the second peak.

As a result, the first peak on the DSC curve is due to esterification reaction and the second to etherification reaction in Figure 7. Therefore, in the epoxy-rich system, the cure proceeds mainly by esterification in the beginning of cure followed by etherification until reaction is stopped. From the observation of the exotherms of DSC curves near the plateau region in Figure 3, the plateau at around $80^{\circ} \mathrm{C}$ is closely related to the change of reaction mechanisms from esterification to etherification. In other words, the increase of the $T_{\mathrm{g}}$ up to the plateau corresponds to the completion of esterification, and the further increase of the $T_{\mathrm{g}}$ to etherification. At higher temperatures, the larger amount of etherification reaction causes the $T_{\mathrm{g}}$ increase up to $125^{\circ} \mathrm{C}$. In our laboratory, experiments are being carried out to identify the change of the reaction mechanisms by means of Fourier Transform Infra-Red Spectroscopy.

\section{CONCLUSIONS}

In order to study the cure behavior of an epoxyanhydride-imidazole system, variation of $T_{\mathrm{g}}$ for two mixtures, one a stoichiometric and the other an epoxyrich, was examined using differential scanning calorimetry (DSC). There was a great increase in the $T_{\mathrm{g}}$ during curing for both systems. Activation energies obtained in this experiment by the time-temperature shift were 15.2 and $16.5 \mathrm{kcal} \mathrm{mol}^{-1}$ for the stoichiometric and epoxyrich formulations, respectively.

For the excess epoxy system, plateaus were observed on the $T_{\mathrm{g}} v s$. cure time curves, which becomes more clear as cure temperature is lower. This can be explained by the residual exotherms from DSC scans. There were two exothermic peaks on the DSC curves initially. As the cure proceeds, the area of the first peak decreases first and then that of the second steadily decreases. The variation of the peaks is closely related to the competitive reactions between esterification for the first peak and etherification for the second. From the observation of the peak variation, the etherification becomes significant after esterification reaction is nearly depleted. Therefore, the increase of $T_{\mathrm{g}}$ up to the plateau observed at about $80^{\circ} \mathrm{C}$ in the $T_{\mathrm{g}} v s$. cure time curves corresponds to the completion of esterification, and the further increase of the $T_{\mathrm{g}}$ is due to etherification. At higher temperatures, the larger amount of etherification reaction occurs and induces the increase of the $T_{\mathrm{g}}$ up to $125^{\circ} \mathrm{C}$.

Acknowledgments. This paper was supported in part by NON DIRECTED RESEARCH FUND, Korea Research Foundation. 


\section{REFERENCES}

1. G. Wisanrakkit and J. K. Gillham, J. Coating Tech., 62, 35 (1990).

2. A. Osei-Owusu, G. C. Martin, and J. T. Grotto, Polym. Eng. Sci., 31, 1604 (1991)

3. V. Micro, Z. Q. Cao, F. Mechin, and J. P. Pascault, Am. Chem. Soc., Polym. Mater. Sci. Eng. Prepr., 66, 451 (1992).

4. P. A. Oyanguren and R. J. J. Williams, J. Appl. Polym. Sci., 47, 1371 (1993).

5. S. L. Simon and J. K. Gillham, J. Appl. Polym. Sci., 46, 1245
(1992).

6. R. F. Fischer, J. Polym. Sci., 44, 155 (1960).

7. G. Stevens, J. Appl. Polym. Sci., 26, 427 (1981).

8. Y. Tanaka and H. Kakiuchi, J. Macromol. Chem., 1, 307 (1966).

9. L. Matejka, J. Lovy, S. Pokorny, K. Bouchal, and K. Dusek, J. Polym. Sci., Polym. Chem. Ed., 21, 2873 (1983).

10. L. Shechter and J. Wynstra, Ind. Eng. Chem., 48, 86 (1956).

11. Y. Tanaka and H. Kakiuchi, J. Polym. Sci., A, 2, 3405 (1964).

12. W. X. Zukas, J. Appl. Polym. Sci., 53, 429 (1994).

13. J. K. Lee and K. D. Pae, Polym. J., 26, 1093 (1994).

14. J. Berger and F. Lohse, Polym. Bull., 12, 535 (1984).

15. J. Berger and F. Lohse, J. Appl. Polym. Sci., 30, 531 (1985). 